\title{
REVIEW
}

\section{Transfusion transmitted leishmaniasis. What to do with blood donors from endemic areas?}

\section{Pasquale Mansueto a , Aurelio Seidita ${ }^{a}$, Giustina Vitale ${ }^{a}$, Antonio Cascio ${ }^{\text {b,* }}$}

\author{
a Department of Internal Medicine and Biomedicine, University of Palermo, Italy \\ b Department of Human Pathology, University of Messina, Italy
}

Received 10 April 2014; received in revised form 11 October 2014; accepted 13 October 2014 Available online 22 October 2014

\section{KEYWORDS \\ Blood donors; \\ Leishmania; \\ Leishmaniasis; \\ Transfusion}

\begin{abstract}
Summary Leishmaniasis clinical spectrum ranges from cryptic infection to fatal visceral leishmaniasis. Cryptic infection can be found in blood donors from areas endemic for leishmaniasis all over the world. Although leishmaniasis is a classic vector-borne disease, cases of transfusion transmitted leishmaniasis have been reported especially in nonendemic areas. Most of these cases regarded infants or children. This paper reviews the literature on this specific feature and the impact of leishmaniasis on transfusion medicine. Relevant literature was found through PubMed. The reference lists of selected articles identified further sources. Conclusions: Blood donations by emigrants or travelers from endemic areas require special attention. Routine diagnostic methods should be implemented in blood banks to exclude donors that are positive for Leishmania, and individuals who suffered from visceral leishmaniasis should be prohibited from donating blood. The use of leukodepletion filters at the time of collection should be recommended in at-risk areas especially for high-risk recipients.
\end{abstract}

(c) 2014 Published by Elsevier Ltd.

\section{Introduction}

Leishmaniasis is a vector-borne disease caused by Leishmania species of protozoan parasites. Among 15 wellrecognized Leishmania spp. known to infect humans, 13

\footnotetext{
* Corresponding author. UOC Malattie Infettive, AOU Policlinico "G. Martino", Via Consolare Valeria n. 1, 98125 Messina, Italy. Tel.: +39090 2213680; fax: +39090692610.

E-mail address: acascio@unime.it (A. Cascio).
}

have a zoonotic nature since canines and rodents are the principal hosts [1]. The clinical spectrum of the disease depends largely on parasite species and host immune response, ranging from asymptomatic infection $(80-95 \%$ of affected people) to 3 main clinical syndromes $(5-20 \%$ of current leishmaniasis): visceral leishmaniasis (VL), also known as "kala-azar," cutaneous leishmaniasis (CL), and mucosal or mucocutaneous leishmaniasis (ML), also known as "espundia" [2,3].

The most severe form is VL which affects about 200,000-400,000 people worldwide, causing approximately 
20,000-30,000 deaths per year. If untreated it has a mortality rate of almost $100 \%$. India, Nepal, Bangladesh, Sudan and Brazil account for $90 \%$ of all visceral cases, Brazilian cases represent up to $90 \%$ of all cases in the Americas. VL usually presents with fever, splenomegaly, pancytopenia and hypergammaglobulinemia [4].

Leishmania (L.) infantum in the Mediterranean basin, West Africa, and South America (L. infantum chagasi (or $L$. infantum MON 1)) is the agent of zoonotic visceral leishmaniasis (ZVL), and dogs are the only confirmed primary reservoir of infection [5]. L. donovani causes anthroponotic $\mathrm{VL}$ in the Indian subcontinent and eastern Africa.

In the 90 s an increase in cases was noticed mainly due to the extension of Leishmania-HIV coinfection. It is estimated that in southern Europe between $25 \%$ and $70 \%$ of adult VL cases are related to HIV infection $[6,7]$. The increased rate of human VL in HIV-infected patients suggests that most cases could be attributable either to a reactivation of cryptic forms of the disease by HIV immune system suppression or the inability to avoid primary infections [8].

Although VL is the most severe form of the disease, $\mathrm{CL}$ is by far the most common, $90 \%$ of which occurs in Afghanistan, Iran, Saudi Arabia, Syria, Brazil, and Peru [9]. $\mathrm{CL}$ clinical onset is characterized by skin ulcers on the exposed parts of the body, such as the face, arms and legs, their number ranging from 1 to as many as 200, causing serious disability and leaving the patient permanently scarred. Sometimes the cutaneous form may evolve to a disseminated form, known as diffuse cutaneous leishmaniasis (DCL). The main species involved in $C L$ are: $L$. tropica, $L$. aethiopica, $L$. major, and dermotropic zymodemes of $L$. infantum in the "Old World" (i.e. southern Europe, Mediterranean basin, Middle East, Asia, and Africa), and parasites belonging to the Leishmania Mexicana ( $L$. amazonensis, L. mexicana, L. venezuelensis) and Leishmania Viannia (L. braziliensis, L. guyanensis, L. panamensis, L. peruviana) subgenus complexes in the "New World" (Latin America). Most of the Old World species cause benign cutaneous disease, New World species cause a spectrum of disease, ranging from mild cutaneous disease to severe mucosal lesions (i.e. ML) [10].

The third form, ML, can lead to extensive and disfiguring destruction of mucous membranes of the nose, mouth and throat cavities and can even involve the cartilages. Bolivia, Brazil and Peru are the most involved Countries, accounting for about $90 \%$ of all cases [11]. As mentioned above just a small number of New World CL evolves into mucosal forms; in these cases its course is chronic and may be lifethreatening. Mucocutaneous lesions are quite frequent complications of the L. Viannia complex infections (more commonly manifesting in L. braziliensis than in L. guyanensis or $L$. panamensis infections), whereas they are not typically seen in L. Mexicana complex infections, except (rarely) when L. amazonensis is involved [12]. All the Leishmania spp responsible for $\mathrm{CL}$ and $\mathrm{ML}$, apart from $L$. tropica are zoonotic.

Hematophagous female sand flies (order Diptera, family Psychodidae, subfamily Phlebotominae) of the Phlebotomus genus in the Old World, and of the Lutzomyia genus in the New World, are the vectors of the disease. Nevertheless, fewer than 50 of the approximately 1000 species of sand flies worldwide are counted as vectors. This could be due to both the inability of some sand fly species to support the development of parasite infective stages in their gut, and to the lack of ecological contact with reservoir hosts [13]. Female sand flies acquire the infective form of the parasite (amastigotes) during blood meals, and transmit the evolved, extracellular, stationary phase, metacyclic promastigotes, to new hosts through another meal. Promastigotes are then phagocytosed by macrophages and related cells (monocytes in the blood and in the remainder of the reticuloendothelial system) in the mammalian host, and transformed to amastigotes [14]. Possible transmission routes other than insects have rarely been reported: placenta, semen, injection needles, organ transplantation, blood transfusion and laboratory-acquired infections [15-22].

However, much attention has recently focused on iatrogenic and preventable causes of leishmaniasis that include the transfusion-transmitted route. In infected human hosts, the overwhelming majority of Leishmania organisms reside within reticuloendothelial cells and do not circulate freely in the blood. At the time of blood collection, organisms are present inside monocytes of infected donors. Upon storage at $4{ }^{\circ} \mathrm{C}$, the organisms remain within white blood cells (WBCs) for some time, but could eventually emerge as free amastigotes that may transform into promastigotes, able to survive outside the cell in the stored blood [23].

The evidence of human cases of transfusion transmitted leishmaniasis (TTL) is of interest, especially VL, with clinical features and outcomes similar to those of the natural infection, not only in endemic but also in nonendemic areas [24].

In this paper we reviewed the literature on clinical and non-clinical features of TTL and its impact on transfusion medicine. We researched the PubMed database for the period from 1980 through December 31, 2013, using the words "leishmaniasis," "transfusion," and "blood donor." Articles presenting original data on human cases of TTL were included in our review, as were the review articles.

\section{Survival of Leishmania spp. in vitro and in experimental animals in blood and blood products}

In vitro studies have clearly shown that, under general blood bank storage conditions, for at least 25 days postdonation, L. tropica- or L. donovani-contaminated transfusion blood products must be considered at risk. Packed red blood cells, frozen-deglycerolized red blood cells, platelet concentrate, and whole blood have been reported to be involved. In contrast, no reports on fresh frozen plasma have been published, as would be expected. Intracellular parasites survive longer than stationary phase extracellular promastigotes or free amastigotes. The parasites survive for 25 days as intracellular forms in monocytes in the red blood cell fraction kept at $4{ }^{\circ} \mathrm{C}$, for 35 days in the red blood cell fraction frozen with glycerol, for 5 days in the platelet fraction kept at $24^{\circ} \mathrm{C}$, and for 30 days in unprocessed whole blood left at $4{ }^{\circ} \mathrm{C}$. To define the minimum concentration of $L$. tropica needed to 
contaminate $1 \mathrm{~mL}$ of blood, serial dilutions with known numbers of intramonocytic amastigotes per milliliter of blood were cultured in whole blood at $4{ }^{\circ} \mathrm{C}$; to determine parasite availability specific aliquots were removed every day. The study proved that when whole blood was kept under blood bank conditions, a single L. tropica parasite survived for 15 days, whereas a 35-day culture inoculum of at least 256 organisms was required to have viable parasites. Animal studies were carried out to assess the presence of infected monocytes in the blood of cutaneously infected animals and the possibility of transmitting the disease by blood transfusion from both infected donor animals and seeded citrate phosphate dextrose-adenine1 (CPDA-1) bags of human whole blood kept for 30 days at $4{ }^{\circ} \mathrm{C}$ under blood bank conditions. Viscerotropic $L$. tropica was cultured from the blood of 6 of 10 cutaneously infected hamsters, whereas cutaneous $L$. major from 5 of 9 cutaneously infected BALB/C mice. In 3 of the 5 mice transfused with a fresh $0.5 \mathrm{~mL}$ blood sample from lesion positive BALB/ $C$ donor mice, cutaneous lesions or metastasis to the lower extremities were observed. In addition, L. major amastigotes were visualized and cultured from the liver and spleen of 4 of the 5 transfused animals. Similarly, of the 5 mice transfused with blood stored for 30 days at $4{ }^{\circ} \mathrm{C}, 4$ developed metastasis to the face and upper extremities, and amastigotes were evidenced and cultured from the livers of all 5 transfused animals. In this study by Grogl et al., 3 additional animals that received $0.25 \mathrm{~mL}$ of blood from a CPDA-1 bag seeded with $10 \mathrm{~L}$. tropica amastigotes per $\mathrm{mL}$ of blood stored for 30 days developed the same metastasis to the lower extremities or face. Thus it was clearly proven that Leishmania not only survive under blood bank conditions, but the parasites retain their infectivity to healthy experimental animals [23]. TTL has also been confirmed in dogs [25-27], and in experimental assays with hamsters and mice, by plasma transfusion as well [28-30].

\section{In vivo human findings of Leishmania in peripheral blood}

Leishmania is expected to persist in the blood for an undefined period between sand fly inoculation and its final localization in the target organs. Several in vivo studies proved that the parasite, after entering the skin through the blood meal, invades the cells of the reticuloendothelial system where it resides and multiplies. Large mononuclear cells and polymorphonuclear leukocytes are the location to search for the parasites. The disease usually starts with an asymptomatic subclinical period, in which parasites may already be circulating in the peripheral blood, but the lack of any clinical or hematologic changes leads physicians to not suspect and diagnose the disease. These potentially asymptomatic parasite infected blood donors usually have a very low parasite density (ranging from 0.001 parasites $/ \mathrm{mL}$ to 1 parasite $/ \mathrm{mL}$ ), in contrast to VL patients at diagnosis, who usually have higher titers (ranging from 8 to $1,400,000$ parasites $/ \mathrm{mL}$ ), and may serve as a source of TTL $[2,31,32]$.

Several studies suggest that the presence of Leishmania in the peripheral blood of asymptomatic carriers is probably episodic, suggesting that such individuals are asymptomatic carriers for a variable period [18,33-60]. The length of this potentially infective period depends both on the virulence of the parasite itself (especially zymodeme MON-1) [61], and on the activity of the cellular immune system of the subject. Some studies have reported long asymptomatic incubation periods; furthermore, the parasite can persist in infected subjects after clinical recovery. In regard to the infecting species, for $L$. donovani this period varies from 1 to 14 months $[23,62]$, whereas for other species this period ranges from 2 to 8 weeks, although some cases have been reported with more than a one-year incubation period. Usually asymptomatic infection does not persist for more than one year, but rarely might persist for decades (up to 30 years) [63]. Furthermore, although lower in impact, extracellular circulation of $L$. braziliensis in healed cases of $M L$ and $L$. donovani, in patients with asymptomatic infections have been reported [63-65]. Finally, clinical recovery of $\mathrm{VL}$ is not always accompanied by parasitological eradication; low parasite titers can be present in the blood of patients who will not present a relapse [66].

\section{Asymptomatic cases of Leishmania infection and studies on blood donors}

Asymptomatic cases of Leishmania infection, especially VL, including the ones reported in apparently healthy blood donors, have been reported in India [33,34], Nepal [35], Bangladesh [36], Iran [37,38], Iraq [60], Turkey [39,40], Italy [41-43], Greece [44], France [45,46], Spain $[18,47,48]$, and Brazil [49-51,53-59].

Quite recently, Scarlata et al. evaluated the risk of transfusion-transmitted VL in an area of south-western Sicily, Italy (area in which the incidence of symptomatic $\mathrm{VL}$ is higher than the Sicilian average): 1449 blood donors were screened for anti-Leishmania antibody positivity by IFAT. PCR to detect Leishmania DNA was used to test blood samples from IFAT-positive donors. Anti-Leishmania antibodies were found in $11(0.75 \%)$ cases, among which Leishmania DNA was detected in four [41]. A previous screening of asymptomatic blood donors from northwestern Sicily, Italy did not detect any positive sample of L. infantum antibodies by ELISA [42]. These data confirm that the risk of TTL seems to be variable in different endemic/non-endemic Sicilian areas [41].

In 1997, Kubar et al. demonstrated Leishmania exposure by Western blot in 61 of 463 donors in Monaco, Southern France, with positive blood cultures in 9 of 61 [45]. Some years later, the same group in Monaco, Southern France, assessed whether $L$. infantum circulated in peripheral blood of blood donors with no history of VL. Sera from 565 subjects were screened by Western blot to detect Leishmania-specific antibodies and identify individuals with probable past exposure to Leishmania. Seropositivity was found in 76 donors whose $B C s$ were subsequently examined by PCR and direct culture. The parasite minicircle kinetoplast DNA was amplified from blood samples of 9 donors. Promastigotes were detected by culture in blood samples from 9 donors. Only 2 donors were found to be positive by PCR and culture [46].

More recently, Kyriakou et al. studied the clinical utility of flow cytometry for the screening of blood donors in the 
endemic area of Lasithi (Crete), Greece, analyzing samples from 2000 blood donors by flow cytometry after labeling with a polyclonal anti-Leishmania antibody, conjugated with fluorescein-isothiocyanate, derived from infected canines in the area. Serum anti-Leishmania antibody search, May-Grünwald staining of peripheral blood smears, and PCR in $B C$ to identify the minicircle of kinetoplastic DNA, were simultaneously performed on the same blood samples. Flow cytometry detected 33 cases $(1.65 \%)$, which were all confirmed by PCR. After pre-storage leukodepletion, no sample was positive by PCR. Anti-Leishmania antibodies were positive in 304 (15\%) cases. Therefore, flow cytometry was found to be a sensitive and rapid method to detect Leishmania in peripheral blood samples, with an efficacy overlapping PCR. At the same time the study proved that leucodepletion effectively reduces parasite presence, thus minimizing the potential risk of Leishmania transmission through blood transfusions in endemic areas. Unfortunately flow cytometry is not always available, as it requires expensive equipment and expertise for the interpretation of results [44].

In 2004 Riera et al. evaluated the extent of cryptic leishmaniasis in blood donors from a Spanish endemic area, (Eivissa, Balearic Islands) using several immunological and parasitological methods. Sera from 656 blood donors were examined: 16 (2.4\%) were positive by ELISA and 50 (7.6\%) by Western blot. Delayed type hypersensitivity (DTH) tests were positive in 15/67 donors (22.3\%). Peripheral blood mononuclear cells (PBMC) and BC samples were analyzed by nested-PCR and culture. DNA of $L$. infantum was amplified in PBMC of 27 (22.1\%) over the 122 analyzed samples. Parasites were isolated in 3 (4.5\%) of $67 \mathrm{BC}$ cultures and the strains were identified as $L$. infantum zymodeme MON-28 [47].

More recently in 2008 the same authors studied the prevalence of Leishmania infection in 1437 blood donors from other Balearic Islands (Majorca, Formentera, and Minorca). In addition, they used nested PCR in the red blood cell $(\mathrm{RBC})$ units to test the efficiency of leukoreduction by filtration to remove the parasite. Anti-Leishmania antibodies were detected in 44 of the 1437 tested blood donors (3.1\%). DTH was performed on 73 of 304 donors randomly selected from Majorca, $8(11 \%)$ of whom were found positive. L. infantum DNA was amplified in PBMC in 18 (5.9\%), and cultures were positive in $2(0.6 \%)$. After leukodepletion all the RBC samples tested (13 of 18) from donors with a positive PBMC nested PCR yielded negative nested PCR results. The authors concluded that DTH and $L$. infantum nested PCR appear to be more sensitive to detect asymptomatic infection than the serology. The use of leukodepletion filters appears to efficiently remove parasites from RBC units [48].

França Ada et al. detected Leishmania asymptomatic infection in 430 blood donors from the Midwest region of Brazil. Serum samples were tested by IFAT, and an interview with the blood donors was carried out. Antibodies were detected in $15.6 \%$ of samples. The variables associated with the infection were: origin of the donor (in this case, the city of Campo Grande, the main endemic area of the state), presence of parks or squares (i.e. suitable environment for the development of vectors of $L$. infantum chagasi), presence of dog with clinical signs of leishmaniasis (e.g., skin lesions, limb paresis) in the neighborhood, and vicinity of leishmaniasis (history of contact with people who had or died of leishmaniasis), confirming the role of these patients as reservoirs [57].

Finally, in another VL endemic area in the same state, Silva et al. evaluated a total of 1241 residents, who underwent anamnesis, clinical examination, and blood collection for Leishmania serological testing (i.e. ELISA and IFAT). DHT (Montenegro skin test), was also performed in all the subjects. In addition, peripheral blood was collected from a randomly selected portion of this population ( $n=149$ ) for genus-specific PCR analysis. Forty-nine (32.9\%) of them had a positive PCR result and none of them developed the disease within a follow-up period lasting 3 years. No association was observed between the results of PCR, serological and skin tests. The authors concluded that a positive PCR result in subjects from the endemic area does not indicate a risk of progression to $\mathrm{VL}$, nor is it associated with a positive result in the serological tests [58].

\section{Transfusion transmitted leishmaniasis}

In the current international literature, to our knowledge, there are only a few published cases of TTL, for several reasons. Among these, one of the most important is related to the geographical area of transmission; this occurs prevalently in endemic areas, where the evidence of transmission by transfusion is extremely difficult to obtain. Another factor is the silent nature of infection in immunecompetent subjects. Moreover, without a high level of clinical suspicion, even a symptomatic recipient of an infected transfusion is likely to be unrecognized as such, and labeled with a diagnosis of "fever of unknown origin." The identification of the TTL cases is also difficult due to the high number of cases in which infection is present; even with a high level of suspicion, blood cultures and spleen aspirates are negative. An additional level of difficulty is caused by the long time the physicians take to diagnose leishmaniasis from the appearance of symptoms, which usually ranges from 1 to 16 months. Until recently it was very likely that most transmission by transfusion occurred in endemic areas. However, recent changes in immigration patterns, disease migration, and travel, owing to environmental changes, have altered the main features of the disease in nonendemic areas, to which is added an increase of susceptible, immune-depressed, individuals (i.e. infants with immature immune systems, HIV-positive population, patients on steroids for asthma or chronic obstructive pulmonary disease, patients undergoing treatment for malignancies, and recipients of organ transplants). The combination of a predisposed high-risk population, which often undergoes transfusions, with a pool of healthy, immune-competent, and therefore, asymptomatic donors, creates ideal conditions for transmission of the parasite and the onset of the disease. In addition, more than $95 \%$ of $L$. donovani and $L$. infantum infections do not progress to clinically apparent visceral disease, in spite of the persistence of visceral infection, demonstrating how likely it would be for Leishmania to be undetected in an infected donor. Therefore, the number of 
diagnosed TTL might be much lower than the true number $[24,67,68]$.

Excluding one highly uncertain case report [69], between 1948 and 2011, we could find only 11 reports of TTL in the English literature, all from nonendemic areas. Of these, 10 were individual case reports, whereas the last one, from Brazil, analyzed 32 cases of kala-azar identified out of 82 patients undergoing hemodialysis and multiple transfusions. Of these cases, most regarded infants (neonates) or children. Due to the usually large number of possible donors the infected ones were identified in only 4 out of the 11 reports on TTL. However, it was not possible to demonstrate the presence of the parasite circulating either in the bloodstream of any of the donors or in transfused blood components. All 4 donors were asymptomatic at the time of blood donation [24,70-72].

In 1948 Chung et al. reported the first transfusiontransmitted kala-azar cases in China. The blood was donated from an infected mother to 2 daughters, aged four and six years old. The mother's blood $(20 \mathrm{~mL})$ had been given by intramuscular injection as a prophylaxis for measles prevention. A few days later the mother was admitted to a local hospital for fever, paleness, and distension of the abdomen and was diagnosed with kala-azar one month later. Both daughters were closely observed and developed kala-azar nine and ten months after receiving the transfusion [71]. Other reports of transfusion-transmitted kalaazar following these 2 case reports were reported from France, Sweden, Belgium, United Kingdom, Greece, India, Colombia and Brazil [24,49,70,72-77]. In September 1955 a 44-year-old French man donated his blood to 2 newborn infants after he had traveled to Spain. A few weeks later he developed skin rash and lymph-adenopathy. The scraping from the skin nodules showed amastigotes. The 2 infants developed anemia after 10 months, which progressed to kala-azar. Bone marrow analysis of one child was found positive for $L$. infantum. The other infant died within three months [72]. Another two cases of transfusion-transmitted kala-azar have been reported in Sweden. Blood from a healthy asymptomatic donor who had recently traveled outside that country was transfused to 2 newborns. In the following six months both recipients fell ill. One of them did not survive and an autopsy revealed kala-azar. Based on the pathological diagnosis of Kala-azar, the second new born was treated and survived [77].

In 1991 the first case of TTL was reported in Belgium in an 11-month-old infant who had never left his native country. Shortly after birth, the child was repeatedly transfused for anemia. The period of incubation was 9 months [73]. A post-operative and post-transfusion case of VL, also affecting a child, was reported in United Kingdom in 1995. Neither the child nor his mother had ever been out of the UK [74].

While all the above reported cases describe $\mathrm{VL}$ in infants, Mpaka et al. reported the case of a 77-year-old Greek woman with renal failure on hemodialysis, admitted to an intensive care unit (ICU) with vascular instability requiring vasopressor treatment. Bone marrow analysis demonstrated multiple intra-cellular Leishmania amastigotes. After liposomal amphotericin B was administered, the patient experienced a quick clinical response. Unfortunately, ten days after admission, the patient died from uncontrolled septic shock from a secondary bacterial infection. Non-vector transmission could be suspected in this case, since the patient had undergone cholecystectomy three months earlier, during which two blood units had been transfused. A subsequent serological analysis of the two donors found they were positive for IgG antiLeishmania antibodies, at a high titer in one of them. A probable large parasite load from the blood transfusion during cholecystectomy, in an old debilitated patient, was probably the cause of the rather rapid presentation of the infection, and the unexpected deterioration to cardiovascular instability needing vasopressor therapy, in the clinical form of septic shock [70].

In India Singh et al. reported the first two cases of probable transfusion-transmitted kala-azar. The first patient was a 6-year-old boy from Uttar Pradesh, Northern India, a nonendemic area. He was on maintenance therapy for acute lymphoblastic leukemia and had received several blood transfusions. The second patient was a 30-year-old woman from Haryana near Delhi, another nonendemic area. After the delivery of her fifth child she suffered from recurrent hemorrhoid bleeding, causing a severe anemia, which required transfusions on two occasions. Both patients had never visited any area endemic for L. donovani [75]. Dey et al. reported another Indian case of a transfusiontransmitted fatal kala-azar in a child who acquired this infection within a few days of his birth after receiving blood from his maternal uncle. The man, who was asymptomatic at the time of blood donation, died within three months due to severe kala-azar. At the onset the baby developed fever and hepatosplenomegaly within one month of blood transfusion and, in spite of repeated anti-leishmanial treatment with sodium antimony gluconate, the child died at the age of 7 months. The mother's seronegative status for leishmaniasis ruled-out the possible congenital transmission of the disease. Moreover, because no other family member suffered from kala-azar at the time of illness, the possibility of vector borne acquisition of this parasite was excluded [24]. More recently in 2011, Mestra et al. reported a case of transfusion-transmitted fatal VL, caused by $L$. (L.) mexicana, in a 42-year-old male resident of northwestern Colombia. After developing terminal renal failure due to lupus nephritis, he underwent immunosuppressive therapy to treat the lupus and prevent transplant rejection. He received a renal transplant but to maintain good hemodynamic status he was forced to receive multiple transfusions, for a long time and from many different donors. Multiple intracellular Leishmania amastigotes were demonstrated in both renal biopsy and marrow aspirates. Cultures of the parasite were obtained in NNN medium and the identification of the species was done both by direct immune-fluorescence and PCR-restriction fragment length polymorphism. This data must be considered in function of the specific epidemiology of leishmaniasis in Colombia; it is the country with the highest number of Leishmania species as causative agents of the disease in different clinical forms. Of all the cases annually reported, 99.3\% correspond to $C L$ and $0.4 \%$ to $M L$, whereas VL accounts only for $0.3 \%$. $L$. (L.) infantum is responsible for the $0.3 \%$. However, the VL case reported here was caused by $L$. (L.) mexicana, a species of Leishmania that has been associated exclusively with CL. Most likely the immunosuppressive therapy 
received after the renal transplant enhanced visceralization of L. (L.) mexicana. In this case, when blood was transfused to an immune-suppressed patient, Leishmania parasite behaved as an opportunistic infection and invaded organs of the mononuclear-phagocyte system, causing clinical manifestations compatible with VL [76]. Finally, Luz et al. investigated the prevalence of anti-L. donovani antibodies in 1500 Brazilian blood donors and multiply transfused hemodialysis patients [49]. The fucose-mannose ligand (FML) ELISA, which was shown to have $100 \%$ sensitivity and $96 \%$ specificity for kala-azar, was used to test the sera (81). Among 1194 volunteer blood donors, seroreactivity (positive to ELISA) was found in $9 \%$, increasing to $25 \%$ in a periurban kala-azar focus. However, higher positivity (37\%) was found in multiply transfused hemodialysis patients from Natal, where kala-azar could be considered endemic (a few cases are frequently reported), with sporadic outbreaks in localized regions (endemic and epidemic). Risk factors included blood transfusion (in this sample there were 32 multiply transfused hemodialysis patients), which was significantly associated with the presence of anti-Leishmania antibodies, but did not include potential exposure to sand fly bites. Significantly, the prevalence decreased to $7 \%$ in hemodialysis patients from Rio de Janeiro, where kala-azar is just an occasional occurrence, and strikes $0 \%$ of patients undergoing continuous ambulatory peritoneal dialysis. The prospective analysis of 27 FML-seroreactive donors from Natal revealed amastigotes of Leishmania in the bone marrow of one subject, while 4 had clinical complaints, including hepatosplenomegaly $[49,78]$.

Unlike the previously described cases, a probable platelet transfusion-transmitted kala-azar was highlighted in a child from India, suffering from idiopathic thrombocytopenic purpura, treated with steroids, immunoglobulin and repeated platelet transfusions (6 times) over a period of 2-3 years [79]. Leishmania can easily survive and be infective in the platelet fraction of blood, up to 5 days at $24{ }^{\circ} \mathrm{C}$, the recommended storage period for platelet transfusion. In the same study, Grogl et al., proved that the number of mononuclear cells, which can usually be found in red blood cell or platelet packs, is sufficient to contaminate these blood products with viable Leishmania. However, platelet transfusion-acquired leishmaniasis had not been reported until this case [23].

\section{Screening of blood donors}

Therefore, considering the potential risk of Leishmania transmission through blood transfusion, the need for control of blood products is clearly recognized. This recommendation is primarily related to demographic changes and to increases in international travel and human migration from endemic areas. As an example, in India migration of residents from kala-azar endemic states (i.e. Bihar, West Bengal, and Assam) to Delhi and other Western parts of India for jobs has become a major issue. Among these migrants the high unemployment rates force apparently healthy subjects to sell their blood. The risk of transfusiontransmitted kala-azar may be worsened by the short supply of blood in Delhi. The huge gap between demand and supply of the blood, leads to storage at $4{ }^{\circ} \mathrm{C}$ for a period of 35 days, which is required to kill this parasite under blood banking conditions, in only a small number of units [23].

Although in India most of the professional blood donors are tested for HIV, hepatitis B and C, there are several other infectious agents not routinely screened for, including $L$. donovani. Furthermore, although government blood banks do not accept blood from professional donors, the private ones do, and in most instances the source of blood is kept secret, because proof of infected donors might jeopardize a thriving blood business. In the USA, although no case of TTL has been reported, the Desert Storm operation raised important concerns about the possibility of TTL [23]. Therefore, on November 12, 1991, the Department of Defense issued a statement of a newly recognized form of viscerotropic leishmaniasis due to $L$. tropica among military personnel. Consequently the American Association of Blood Banks (AABB) recommended that individuals who had traveled to or visited Saudi Arabia, Kuwait, Iraq, Oman, Yemen, Qatar, Bahrain or the United Arab Emirates, on or after August 1, 1990, should be deferred as donors of transfusion blood components until January 1, 1993 (for about 12 months), with permanent deferral of subjects with apparent skin infection. This last deferral did not extend to US soldiers in Afghanistan since they had already been deferred because of malaria [80].

Afterwards, AABB suggested applying a blanket policy to better prevent TTL by not drawing blood from individuals who are at potential risk of being infected with the parasite [81]. The US Food and Drug Administration agreed with such a deferral policy as a measure to ensure the safety of the nation's blood supply from transmission of Leishmania [82]. Similarly, in 2009 the Pan American Health Organization recommended permanently refusing blood donations from individuals who have had leishmaniasis, and does not allow donations for a period of at least two years from asymptomatic carriers or subjects with a history of travel or transfusion at risk of being infected [83].The International Forum showed that in most European countries no specific measures are implemented to prevent TTL, since in none of the countries that participated in this International Forum, was TTL observed over the last 10 years. Only Ireland defers donors for 12 months if they have visited Iraq [84]. Finally, there is a concern by the World Health Organization (WHO) to certify the safety of blood, and to make progress in relation to donor recruitment and blood collection, as well as in the routine testing on the samples of these donors [85].

Nevertheless, in the light of published data a reconsideration of transfusion policy seems to be necessary, as the impact on the blood supply is expected to be significant, although, to date, it is difficult to estimate the exact number of donors who will be deferred. Therefore, in this delicate context adequate blood donor screening must be considered the first step.

Diagnosis of leishmaniasis depends both on the clinical symptoms of the infection, and on the antileishmanial antibody titers or detection of the parasite in samples obtained from patients. However, both the low antibody titers and the low number of parasites in samples of individuals with asymptomatic leishmaniasis, make the sensitivity of the actual diagnostic tools insufficient. Immunodiagnostic 
testing, especially ELISA, using recombinant antigens, such as rK-39, developed from L. chagasi of the New World, or a recently developed recombinant antigen rKE16, from Indian $L$. donovani, can be used for mass screening of donor blood samples. Gel diffusion, indirect hemagglutination assay, direct agglutination test, immunochromatographic test, complement fixation, counter-current immune-electrophoresis, indirect fluorescent antibody test (IFAT), and Western Blot represent some other possible serological methods to determine specific Leishmania antibodies in serum samples. However, especially in endemic regions, a positive test for antibodies against Leishmania does not necessarily indicate active infection, but it may just be the result of a previous exposure. In addition, antibodies to Leishmania are not a reliable indicator of donor prevalence or infectivity. They can always be detected in patients with symptomatic visceral infection, whereas they are usually undetectable in patients with asymptomatic viscerotropic infection, and moreover usually become negative after treatment of visceral disease. Therefore, they must be considered a good marker for active visceral disease, but a poor one for asymptomatic infection. Finally, but not less important, these methodologies may have technical and financial limits [52,54,56,86-89].

Parasitological techniques (i.e. direct examination and/ or culture of bone marrow, lymph nodes, liver or spleen) remain the "gold standard" tools to confirm active Leishmania infection. Nevertheless, in epidemiological research these methods are inappropriate, because of both the nature of the samples and the invasive nature of the sampling procedures [86].

In recent years other less aggressive diagnostic tools oriented to detect the parasites have been considered. Several studies have shown that PCR is a useful alternative to traditional methods both for diagnosis and follow-up of leishmaniasis patients (especially those suffering from $V L$ ) and to detect parasitemia in asymptomatic carriers. One of the advantages of PCR is that it can be performed on any biological sample (skin tissue, bone marrow and blood), with high sensitivity [18,32,86,90-95].

In addition, previous studies proved that in endemic areas even if no detectable humoral immune-response can be found, Leishmania DNA might be present in blood from healthy people $[32,47,50,51]$. This last evidence, characterizing asymptomatic infection, has also been observed in dogs with cryptic $L$. infantum infection. It has been concluded that antibody-based testing does not clearly differentiate between non-infected and infected asymptomatic dogs, and that culture and PCR are more reliable diagnostic tools [96-100].

Riera et al. clearly evidenced the underestimation of ELISA in determining prevalence of Leishmania infection in blood donors. They proved that in an endemic area of Spain ELISA had a prevalence of just $2.4 \%$, Western blot $7.6 \%$, and finally nested PCR 22\% [47]. Furthermore, even a well known and proven technique as cultures has shown low sensitivity values compared to PCR, in asymptomatic carriers. This may be due to the low level of circulating parasites in these latter individuals, which is sufficient for PCR positivity but not to provide a positive culture $[47,48]$. This high sensitivity value of nested PCR compared to the lower sensitivity of specific antibody detection techniques, and the rapid clearance of parasite (or dead parasite) DNA, indicate that nested PCR should be used to detect current infections in asymptomatic [32,47,86,90-95,101].

In this context, with the increased concern for blood safety due to emerging pathogens and the threat of bioterror agents, which might be transmissible through blood, the need for rapid pathogen detection becomes even more important. However, the cost and logistical burden of testing for many phylogenetically diverse pathogens call for a multiplex assay. Selvapandiyan et al. developed a multiplex polymerase chain reaction assay able to simultaneously identify the presence of both bacterial ( $B$. anthracis and $Y$. pestis) and parasitic (Trypanosomatid species, including Leishmania) pathogens in blood specimens. To obtain higher sensitivity of the assay, the researchers chose to specifically amplify genes that can be found in multiple copies in the microorganisms [102]. Finally, and in contrast to the above-mentioned consideration on PCR efficacy, other authors argue that little experience with Leishmania primers may lead to falsepositive results, which can be a real concern [103]. However, some physicians believe that universal screening for anti-leishmanial antibodies, discarding the blood of Leishmania-positive donors, would decrease the blood supply. Currently this remains a debatable issue. Further studies appropriately designed to analyze the prevalence and costbenefit ratio of anti-leishmanial antibody screening are needed to determine whether screening needs to become a routine procedure in blood banks [86].

\section{Prevention}

TTL requires parasites to be present in the blood either (and especially) within infected monocytes or (less probably) as free amastigotes released from mononuclear phagocytes. Obviously, the parasites must survive blood processing and storage $[23,104]$. Recently, using in vitro experiments several methods designed to inactivate Leishmania in blood products have been tested. These include the use of riboflavin (as a photosensitizer) and ultraviolet light [105], and the photochemical treatment by amotosalen plus ultraviolet light in platelet concentrates $[106,107]$ as well as by thiopyrylium in RBC suspensions [108].

In the first method, riboflavin can rapidly traverse lipid membranes of the parasite and non-specifically intercalates with nucleic acids. Upon light exposure, the riboflavin causes modification of the pathogen nucleic acid through the oxidation of guanine residues and generation of reactive oxygen species. As a result of these photochemical processes, pathogens in blood products are rendered unable to replicate due to nucleic acid modification. This technology exploits the absence of nucleic acids in all the blood components (including plasma and platelet concentrates), which are beneficial to transfusion, and that instead is present in the parasite [105,109].

In the second method, amotosalen, a synthetic psoralen compound, reversibly intercalates into the helical regions of DNA and RNA. Under UVA light at $320 \mathrm{~nm}-400 \mathrm{~nm}$ exposure, amotosalen forms covalent monoadducts with pyrimidine bases on a single strand of nucleic acid. Further 
exposure to UVA light causes the monoadduct to link with a second pyrimidine base, producing an inter- or intrastrand cross-link, therefore disabling the transcription and replication processes. The cross-linked genomes of pathogens can no longer function or replicate. The system has been successfully used to inactivate a broad spectrum of viruses, bacteria, and parasites (such as Leishmania), in platelet components, not affecting their function and/or structural features. However, this technology is not effective for red blood cells or whole blood, because the UV light does not manage to penetrate sufficiently to activate the amotosalen, and induce nucleic acid cross-linking [106,107].

The third method uses thiopyrylium, a flexible photosensitizer, which intercalates into the helical regions of DNA. Upon $1.1 \mathrm{~J} \mathrm{~cm}^{-2}$ red light, thiopyrylium creates bonds with nucleic acid bases. This cross-linking makes the genome of pathogens no longer functional or able to replicate. The system has been successfully used to inactivate Leishmania in red cell suspensions [108].

The benefits of leukodepletion of blood products to remove several pathogens (e.g. cytomegalovirus, human Tlymphotropic virus, the rickettsial species Orientia tsutsugamushi, and Trypanosoma cruzi) from blood components have been tested, and have led to the increased use of this technique. Leukodepletion filters of different types have been designed to be used at the time of collection or at the time of transfusion. Because Leishmania protozoans are intracellular monocyte pathogens, it seemed theoretically possible to use leukodepletion filters as a means to remove the organisms from infected blood products. Nowadays, the use of leukodepletion filters, especially at collection time, when the organism is predominantly intracellular, or with bedside filters after storage, seems to be the most efficient means to reduce Leishmania transmission hazard. This processing can be particularly useful in at-risk areas and for high-risk (immune-suppressed) recipients, thus improving quality and safety in the collection and transfusion of blood. Nevertheless, due to high costs (about $€ 50$ per blood unit) this procedure is used only in selected cases. In this context, the use of this and other blood protection procedures would be considered mandatory in the case of recipients with co-infections and/or immune-suppression, which appear as aggravating factors triggering greater morbidity. In addition, to complete this complex decision, the high cost of hospitalization for patients with VL cannot be ignored, coupled with the low availability of beds in public hospitals, and the toxicity of drugs used in the treatment $[44,48,110]$.

Use of whole-blood filters at collection causes a 3- to 4log reduction of WBCs $\left(99.31 \%<1 \times 10^{6}\right.$ leucocytes $)$. At this time, considering that all the parasites should be contained within monocytes, there is a direct correlation between the ability of the filter to remove leukocytes and parasite depletion. However, the possible presence of free amastigotes, due to WBC breakdown during filtration, which could survive outside the cells in blood stored at $4{ }^{\circ} \mathrm{C}$, may increase the risk of transmission [23,30,110,111].

Mechanical trapping and charge-related interactions between cells (i.e. promastigotes and extracellular amastigotes) and filter fibers, as well as interactions of cells with WBCs also trapped within the filters, have been shown to be other effective mechanisms to remove promastigotes and extracellular amastigotes, besides the removal of WBCs. For this reason it may be useful to also use bedside filters after storage. Nevertheless, although the leukodepletion system leads to a reduction in parasite detection, the existence of different filtration systems makes further research necessary to determine the efficacy of leukodepletion, with particular regard to other blood components, as well as to determine the usefulness of other methods to remove or inactivate the parasite in blood. In any case, the relatively low number of recently reported cases of TTL in nonendemic areas of Europe might be explained by the widespread use of leukodepletion filters in these regions [110,112].

\section{Conclusion}

The transmission of Leishmania spp through transfusion is a relatively rare although probably underestimated event. Routine diagnostic methods should be implemented in blood banks to exclude donors that are positive for Leishmania. Individuals who suffered from visceral leishmaniasis should be excluded from donating blood. The use of leukodepletion filters at the time of collection should be recommended in at-risk areas especially for high-risk recipients.

\section{Conflict of interest}

None declared.

\section{References}

[1] Gramiccia M, Gradoni L. The current status of zoonotic leishmaniases and approaches to disease control. Int J Parasitol 2005;35:1169-80.

[2] Herwaldt BL. Leishmaniasis. Lancet 1999;354:1191-9.

[3] Mansueto P, Vitale G, Di Lorenzo G, Rini GB, Mansueto S, Cillari E. Immunopathology of leishmaniasis: an update. Int J Immunopathol Pharmacol 2007;20:435-45.

[4] Thornton SJ, Wasan KM, Piecuch A, Lynd LL, Wasan EK. Barriers to treatment for visceral leishmaniasis in hyperendemic areas: India, Bangladesh, Nepal, Brazil and Sudan. Drug Dev Ind Pharm 2010;36:1312-9.

[5] Quinnell RJ, Courtenay O. Transmission, reservoir hosts and control of zoonotic visceral leishmaniasis. Parasitology 2009; 136:1915-34.

[6] Desjeux P, Alvar J. Leishmania/HIV co-infections: epidemiology in Europe. Ann Trop Med Parasitol 2003;97(Suppl. 1): 3-15.

[7] Leishmania/HIV co-infection, south-western Europe, 1990-1998. Releve epidemiologique hebdomadaire/Section d'hygiene du Secretariat de la Societe des Nations = Wkly Epidemiol Rec/Health Sect Secr Leag Nations 1999;74: 365-75.

[8] Alvar J, Canavate C, Gutierrez-Solar B, Jimenez M, Laguna F, Lopez-Velez R, et al. Leishmania and human immunodeficiency virus coinfection: the first 10 years. Clin Microbiol Rev 1997; 10:298-319.

[9] Ameen M. Cutaneous leishmaniasis: advances in disease pathogenesis, diagnostics and therapeutics. Clin Exp Dermatol 2010;35:699-705.

[10] Reithinger R, Dujardin JC, Louzir H, Pirmez C, Alexander B, Brooker S. Cutaneous leishmaniasis. Lancet Infect Dis 2007;7: 581-96. 
[11] Lessa MM, Lessa HA, Castro TW, Oliveira A, Scherifer A, Machado P, et al. Mucosal leishmaniasis: epidemiological and clinical aspects. Braz J Otorhinolaryngol 2007;73:843-7.

[12] Amato VS, Tuon FF, Bacha HA, Neto VA, Nicodemo AC. Mucosal leishmaniasis. Current scenario and prospects for treatment. Acta Trop 2008;105:1-9.

[13] Ready P. Sand fly evolution and its relationship to Leishmania transmission. Memorias do Instituto Oswaldo Cruz 2000;95: 589-90.

[14] Bates PA. Transmission of Leishmania metacyclic promastigotes by phlebotomine sand flies. Int J Parasitol 2007;37: 1097-106.

[15] Meinecke CK, Schottelius J, Oskam L, Fleischer B. Congenital transmission of visceral leishmaniasis (Kala Azar) from an asymptomatic mother to her child. Pediatrics 1999;104:e65.

[16] Caldas AJ, Costa JM, Gama ME, Ramos EA, Barral A. Visceral leishmaniasis in pregnancy: a case report. Acta Trop 2003;88: $39-43$.

[17] Symmers WS. Leishmaniasis acquired by contagion: a case of marital infection in Britain. Lancet 1960;1:127-32.

[18] Martin-Sanchez J, Pineda JA, Morillas-Marquez F, GarciaGarcia JA, Acedo C, Macias J. Detection of Leishmania infantum kinetoplast DNA in peripheral blood from asymptomatic individuals at risk for parenterally transmitted infections: relationship between polymerase chain reaction results and other Leishmania infection markers. Am J Trop Med Hyg 2004;70:545-8.

[19] Morales MA, Chicharro C, Ares M, Canavate C, Barker DC, Alvar J. Molecular tracking of infections by Leishmania infantum. Trans R Soc Trop Med Hyg 2001;95:104-7.

[20] Amela C, Lopez-Gay D, Alberdi JC, Castilla J. Injecting drug use as risk factor for visceral leishmaniasis in AIDS patients. Eur J Epidemiol 1996;12:91-2.

[21] Antinori S, Cascio A, Parravicini C, Bianchi R, Corbellino M. Leishmaniasis among organ transplant recipients. Lancet Infect Dis 2008;8:191-9.

[22] Herwaldt BL, Juranek DD. Laboratory-acquired malaria, leishmaniasis, trypanosomiasis, and toxoplasmosis. Am J Trop Med Hyg 1993;48:313-23.

[23] Grogl M, Daugirda JL, Hoover DL, Magill AJ, Berman JD. Survivability and infectivity of viscerotropic Leishmania tropica from Operation Desert Storm participants in human blood products maintained under blood bank conditions. Am J Trop Med Hyg 1993;49:308-15.

[24] Dey A, Singh S. Transfusion transmitted leishmaniasis: a case report and review of literature. Indian J Med Microbiol 2006; 24:165-70.

[25] Owens SD, Oakley DA, Marryott K, Hatchett W, Walton R, Nolan TJ, et al. Transmission of visceral leishmaniasis through blood transfusions from infected English foxhounds to anemic dogs. J Am Vet Med Assoc 2001;219: 1076-83.

[26] Giger U, Oakley DA, Owens SD, Schantz P. Leishmania donovani transmission by packed RBC transfusion to anemic dogs in the United States. Transfusion 2002;42:381-3.

[27] de Freitas E, Melo MN, da Costa-Val AP, Michalick MS. Transmission of Leishmania infantum via blood transfusion in dogs: potential for infection and importance of clinical factors. Vet Parasitol 2006;137:159-67.

[28] Palatnik-de-Sousa CB, Paraguai-de-Souza E, Gomes EM, Soares-Machado FC, Luz KG, Borojevic R. Transmission of visceral leishmaniasis by blood transfusion in hamsters. Braz $\mathrm{J}$ Med Biol Res = Revista brasileira de pesquisas medicas e biologicas/Sociedade Brasileira de Biofisica [et al] 1996;29: 1311-5.

[29] Morillas-Marquez F, Martin-Sanchez J, Acedo-Sanchez C, Pineda JA, Macias J, Sanjuan-Garcia J. Leishmania infantum (Protozoa, kinetoplastida): transmission from infected patients to experimental animal under conditions that simulate needle-sharing. Exp Parasitol 2002;100:71-4.

[30] Paraguai de Souza E, Esteves Pereira AP, Machado FC, Melo MF, Souto-Padron T, Palatnik M, et al. Occurrence of Leishmania donovani parasitemia in plasma of infected hamsters. Acta Trop 2001;80:69-75.

[31] Michel G, Pomares C, Ferrua B, Marty P. Importance of worldwide asymptomatic carriers of Leishmania infantum ( $L$. chagasi) in human. Acta Trop 2011:119:69-75.

[32] Mary C, Faraut F, Drogoul MP, Xeridat B, Schleinitz N, Cuisenier B, et al. Reference values for Leishmania infantum parasitemia in different clinical presentations: quantitative polymerase chain reaction for therapeutic monitoring and patient follow-up. Am J Trop Med Hyg 2006;75:858-63.

[33] Singh S, Kumari V, Singh N. Predicting kala-azar disease manifestations in asymptomatic patients with latent Leishmania donovani infection by detection of antibody against recombinant K39 antigen. Clin Diagn Lab Immunol 2002;9: 568-72.

[34] Das VN, Siddiqui NA, Verma RB, Topno RK, Singh D, Das S, et al. Asymptomatic infection of visceral leishmaniasis in hyperendemic areas of Vaishali district, Bihar, India: a challenge to kala-azar elimination programmes. Trans R Soc Trop Med Hyg 2011;105:661-6.

[35] Bhattarai NR, Van der Auwera G, Khanal B, De Doncker S, Rijal S, Das ML, et al. PCR and direct agglutination as Leishmania infection markers among healthy Nepalese subjects living in areas endemic for Kala-Azar. Trop Med Int Health: TM IH 2009;14:404-11.

[36] Huda MM, Rudra S, Ghosh D, Bhaskar KR, Chowdhury R, Dash AP, et al. Low prevalence of Leishmania donovani infection among the blood donors in kala-azar endemic areas of Bangladesh. BMC Infect Dis 2013;13:62.

[37] Fakhar M, Motazedian MH, Hatam GR, Asgari Q, Kalantari M, Mohebali M. Asymptomatic human carriers of Leishmania infantum: possible reservoirs for Mediterranean visceral leishmaniasis in southern Iran. Ann Trop Med Parasitol 2008; 102:577-83.

[38] Alborzi A, Pourabbas B, Shahian F, Mardaneh J, Pouladfar GR, Ziyaeyan M. Detection of Leishmania infantum kinetoplast DNA in the whole blood of asymptomatic individuals by PCR-ELISA and comparison with other infection markers in endemic areas, southern Iran. Am J Trop Med Hyg 2008;79:839-42.

[39] Ates SC, Bagirova M, Allahverdiyev AM, Baydar SY, Koc RC, Elcicek S, et al. Detection of antileishmanial antibodies in blood sampled from blood bank donors in Istanbul. Future Microbiol 2012;7:773-9.

[40] Ates SC, Bagirova M, Allahverdiyev AM, Kocazeybek B, Kosan E. Utility of the microculture method for Leishmania detection in non-invasive samples obtained from a blood bank. Acta Trop 2013;128:54-60.

[41] Scarlata F, Vitale F, Saporito L, Reale S, Vecchi VL, Giordano S, et al. Asymptomatic Leishmania infantum/chagasi infection in blood donors of western Sicily. Trans R Soc Trop Med Hyg 2008;102:394-6.

[42] Colomba C, Saporito L, Polara VF, Barone T, Corrao A, Titone L. Serological screening for Leishmania infantum in asymptomatic blood donors living in an endemic area (Sicily, Italy). Transfus Apher Sci: Official Journal of the World Apheresis Association: Official Journal of the European Society for Haemapheresis 2005;33:311-4.

[43] Biglino A, Bolla C, Concialdi E, Trisciuoglio A, Romano A, Ferroglio E. Asymptomatic Leishmania infantum infection in an area of northwestern Italy (Piedmont region) where such infections are traditionally nonendemic. J Clin Microbiol 2010;48:131-6.

[44] Kyriakou DS, Alexandrakis MG, Passam FH, Kourelis TV, Foundouli P, Matalliotakis E, et al. Quick detection of 
Leishmania in peripheral blood by flow cytometry. Is prestorage leucodepletion necessary for leishmaniasis prevention in endemic areas? Transfus Med 2003;13:59-62.

[45] Kubar J, Quaranta JF, Marty P, Lelievre A, Le Fichoux Y, Aufeuvre JP. Transmission of L. infantum by blood donors. Nat Med 1997;3:368.

[46] le Fichoux Y, Quaranta JF, Aufeuvre JP, Lelievre A, Marty P, Suffia I, et al. Occurrence of Leishmania infantum parasitemia in asymptomatic blood donors living in an area of endemicity in southern France. J Clin Microbiol 1999;37:1953-7.

[47] Riera C, Fisa R, Udina M, Gallego M, Portus M. Detection of Leishmania infantum cryptic infection in asymptomatic blood donors living in an endemic area (Eivissa, Balearic Islands, Spain) by different diagnostic methods. Trans R Soc Trop Med Hyg 2004;98:102-10.

[48] Riera C, Fisa R, Lopez-Chejade P, Serra T, Girona E, Jimenez $M$, et al. Asymptomatic infection by Leishmania infantum in blood donors from the Balearic Islands (Spain). Transfusion 2008;48:1383-9.

[49] Luz KG, da Silva VO, Gomes EM, Machado FC, Araujo MA, Fonseca HE, et al. Prevalence of anti-Leishmania donovani antibody among Brazilian blood donors and multiply transfused hemodialysis patients. Am J Trop Med Hyg 1997;57: $168-71$.

[50] Costa CH, Stewart JM, Gomes RB, Garcez LM, Ramos PK, Bozza M, et al. Asymptomatic human carriers of Leishmania chagasi. Am J Trop Med Hyg 2002;66:334-7.

[51] Otero AC, da Silva VO, Luz KG, Palatnik M, Pirmez C, Fernandes O, et al. Short report: occurrence of Leishmania donovani DNA in donated blood from seroreactive Brazilian blood donors. Am J Trop Med Hyg 2000;62:128-31.

[52] Moreno EC, Melo MN, Lambertucci JR, Serufo JC, Andrade AS, Antunes CM, et al. Diagnosing human asymptomatic visceral leishmaniasis in an urban area of the State of Minas Gerais, using serological and molecular biology techniques. Revista da Sociedade Brasileira de Medicina Tropical 2006;39:421-7.

[53] Barao SC, de Fonseca Camargo-Neves VL, Resende MR, da Silva LJ. Human asymptomatic infection in visceral leishmaniasis: a seroprevalence study in an urban area of low endemicity. Preliminary results. Am J Trop Med Hyg 2007;77: 1051-3.

[54] de Gouvea Viana L, de Assis TS, Orsini M, da Silva AR, de Souza GF, Caligiorne R, et al. Combined diagnostic methods identify a remarkable proportion of asymptomatic Leishmania (Leishmania) chagasi carriers who present modulated cytokine profiles. Trans R Soc Trop Med Hyg 2008;102: 548-55.

[55] Oliveira AL, Paniago AM, Sanches MA, Dorval ME, Oshiro ET, Leal CR, et al. Asymptomatic infection in family contacts of patients with human visceral leishmaniasis in Tres Lagoas, Mato Grosso do Sul State, Brazil. Cadernos de saude publica 2008;24:2827-33.

[56] Romero HD, Silva Lde A, Silva-Vergara ML, Rodrigues V, Costa RT, Guimaraes SF, et al. Comparative study of serologic tests for the diagnosis of asymptomatic visceral leishmaniasis in an endemic area. Am J Trop Med Hyg 2009;81:27-33.

[57] Franca Ade O, de Castro VL, Lima Jr MS, Pontes ER, Dorval ME. Anti-Leishmania antibodies in blood donors from the Midwest region of Brazil. Transfus Apher Sci: Official Journal of the World Apheresis Association: Official Journal of the European Society for Haemapheresis 2013;49:627-30.

[58] Silva LA, Romero HD, Fagundes A, Nehme N, Fernandes O, Rodrigues $\mathrm{V}$, et al. Use of the polymerase chain reaction for the diagnosis of asymptomatic Leishmania infection in a visceral leishmaniasis-endemic area. Revista do Instituto de Medicina Tropical de Sao Paulo 2013;55:101-4.

[59] Clemente WT, Rabello A, Faria LC, Peruhype-Magalhaes V, Gomes LI, da Silva TA, et al. High prevalence of asymptomatic Leishmania spp. infection among liver transplant recipients and donors from an endemic area of Brazil. Am J Transplant: Official Journal of the American Society of Transplantation and the American Society of Transplant Surgeons 2014;14:96-101.

[60] Souhaila MA, Khawla HZ, K YAD. Indirect fluorescent antibody test for serodiagnosis of visceral leishmaniasis: an epidemiological study in Iraq. J Univ Anbar Pure Sci 2010;4:1-4.

[61] Hide M, Marion E, Pomares C, Fisa R, Marty P, Banuls AL. Parasitic genotypes appear to differ in leishmaniasis patients compared with asymptomatic related carriers. Int J Parasitol 2013;43:389-97.

[62] Mansueto P, Vitale G, Seidita A, Guarneri FP, Pepe I, Rinollo C, et al. Advances in leishmaniasis immunopathogenesis. Acta Medica Mediterranea 2011;27:7-16.

[63] Guevara P, Ramirez JL, Rojas E, Scorza JV, Gonzalez N, Anez N. Leishmania braziliensis in blood 30 years after cure. Lancet 1993;341:1341.

[64] Martinez JE, Alba, Arias L, Escobar MA, Saravia NG. Haemoculture of Leishmania (Viannia) braziliensis from two cases of mucosal leishmaniasis: re-examination of haematogenous dissemination. Trans R Soc Trop Med Hyg 1992;86:392-4.

[65] Sharma MC, Gupta AK, Das VN, Verma N, Kumar N, Saran R, et al. Leishmania donovani in blood smears of asymptomatic persons. Acta Trop 2000;76:195-6.

[66] Aoun K, Chouihi E, Amri F, Ben Alaya N, Raies A, Mary C, et al. Short report: contribution of quantitative real-time polymerase chain reaction to follow-up of visceral leishmaniasis patients treated with meglumine antimoniate. Am J Trop Med Hyg 2009;81:1004-6.

[67] Cardo LJ. Leishmania: risk to the blood supply. Transfusion 2006;46:1641-5.

[68] Engwerda CR, Ato M, Kaye PM. Macrophages, pathology and parasite persistence in experimental visceral leishmaniasis. Trends Parasitol 2004;20:524-30.

[69] Mauny I, Blanchot I, Degeilh B, Dabadie A, Guiguen C, Roussey M. Visceral leishmaniasis in an infant in Brittany: discussion on the modes of transmission out endemic zones. Pediatrie 1993;48:237-9.

[70] Mpaka MA, Daniil Z, Kyriakou DS, Zakynthinos E. Septic shock due to visceral leishmaniasis, probably transmitted from blood transfusion. J Infect Dev Ctries 2009;3:479-83.

[71] Chung HL, Chow KK, Lu JP. The first two cases of transfusion kala-azar. Chin Med J 1948;66:325-6.

[72] Andre R, Brumpt L, Dreytus B, Puseleg A, Jacob S. Leishmaniose Cutanee. Leishmaniose cutanee ganglionnare et kala-azar transfusional. Trop Dis Bull 1958;55:379-81.

[73] Cohen C, Corazza F, De Mol P, Brasseur D. Leishmaniasis acquired in Belgium. Lancet 1991;338:128.

[74] Cummins D, Amin S, Halil O, Chiodini PL, Hewitt PE, RadleySmith R. Visceral leishmaniasis after cardiac surgery. Arch Dis Child 1995;72:235-6.

[75] Singh S, Chaudhry VP, Wali JP. Transfusion-transmitted kalaazar in India. Transfusion 1996;36:848-9.

[76] Mestra L, Lopez L, Robledo SM, Muskus CE, Nicholls RS, Velez ID. Transfusion-transmitted visceral leishmaniasis caused by Leishmania (Leishmania) mexicana in an immunocompromised patient: a case report. Transfusion 2011;51:1919-23.

[77] Kostman R, Barr M, Bengtson E, Garnham PC, Hult G. Kalaazar transferred by exchange blood transfusion in two Swedish infants. In: Proceedings of the seventh international congress of tropical medicine and malaria. Geneva, Switzerland: World Health Organization; 1963. p. 384.

[78] Palatnik-de-Sousa CB, Gomes EM, Paraguai-de-Souza E, Palatnik M, Luz K, Borojevic R. Leishmania donovani: titration of antibodies to the fucose-mannose ligand as an aid in diagnosis and prognosis of visceral leishmaniasis. Trans R Soc Trop Med Hyg 1995;89:390-3. 
[79] Mathur P, Samantaray JC. The first probable case of platelet transfusion-transmitted visceral leishmaniasis. Transfus Med 2004;14:319-21.

[80] Hillyer CD, Josephson CD, Blajchman MA, Vostal JG, Epstein JS, Goodman JL. Bacterial contamination of blood components: risks, strategies, and regulation: joint ASH and $A A B B$ educational session in transfusion medicine. Hematology/the Education Program of the American Society of Hematology American Society of Hematology Education Program 2003:575-89.

[81] Bosch X. USA blocks blood donation in bid to prevent leishmaniasis. Lancet Infect Dis 2003;12:746.

[82] Food and Drug Administration. Potential recommendation on blood donor deferral for Leishmaniasis and exposure to Leishmania. Blood Products Advisory Committee; 2003. http://wwwfdagov/ohrms/dockets/ac/03/briefing/ 4014b1htm.

[83] Organization PAH. Eligibility for blood donation: recommendations for education and selection of prospective blood donors. 2009. http://www2pahoorg/hq/dmdocuments/ 2009/EligiBlood09ENpdf.

[84] Reesink HW. European strategies against the parasite transfusion risk. Transfusion clinique et biologique: journal de la Societe francaise de transfusion sanguine 2005;12:1-4.

[85] Bloch EM, Vermeulen M, Murphy E. Blood transfusion safety in Africa: a literature review of infectious disease and organizational challenges. Transfus Med Rev 2012;26:164-80.

[86] Singh S. New developments in diagnosis of leishmaniasis. Indian J Med Res 2006;123:311-30.

[87] Sivakumar R, Sharma P, Chang KP, Singh S. Cloning, expression, and purification of a novel recombinant antigen from Leishmania donovani. Protein Expr Purif 2006;46:156-65.

[88] Mansueto P, Pepe I, Seidita A, Scozzari F, Vitale G, Arcoleo F, et al. Significance of persistence of antibodies against Leishmania infantum in Sicilian patients affected by acute visceral leishmaniasis. Clin Exp Med 2012;12:127-32.

[89] Visceral leishmaniasis rapid diagnostic test performance. Diagnostics evaluation series no 4. Geneva, Switzerland: World Health Organization (WHO); 2011.

[90] Josephson KL, Gerba CP, Pepper IL. Polymerase chain reaction detection of nonviable bacterial pathogens. Appl Environ Microbiol 1993;59:3513-5.

[91] Fisa R, Riera C, Ribera E, Gallego M, Portus M. A nested polymerase chain reaction for diagnosis and follow-up of human visceral leishmaniasis patients using blood samples. Trans R Soc Trop Med Hyg 2002;96(Suppl. 1):S191-4.

[92] Riera C, Fisa R, Ribera E, Carrio J, Falco V, Gallego M, et al. Value of culture and nested polymerase chain reaction of blood in the prediction of relapses in patients co-infected with leishmania and human immunodeficiency virus. Am J Trop Med Hyg 2005;73:1012-5.

[93] Lachaud L, Dereure J, Chabbert E, Reynes J, Mauboussin JM, Oziol E, et al. Optimized PCR using patient blood samples for diagnosis and follow-up of visceral Leishmaniasis, with special reference to AIDS patients. J Clin Microbiol 2000;38:236-40.

[94] Cruz I, Canavate C, Rubio JM, Morales MA, Chicharro C, Laguna $\mathrm{F}$, et al. A nested polymerase chain reaction (Ln-PCR) for diagnosing and monitoring Leishmania infantum infection in patients co-infected with human immunodeficiency virus. Trans R Soc Trop Med Hyg 2002;96(Suppl. 1):S185-9.

[95] Antinori S, Calattini S, Longhi E, Bestetti G, Piolini R, Magni $C$, et al. Clinical use of polymerase chain reaction performed on peripheral blood and bone marrow samples for the diagnosis and monitoring of visceral leishmaniasis in HIVinfected and HIV-uninfected patients: a single-center, 8-year experience in Italy and review of the literature. Clin Infect Dis: an Official Publication of the Infectious Diseases Society of America 2007;44:1602-10.
[96] Berrahal F, Mary C, Roze M, Berenger A, Escoffier K, Lamouroux D, et al. Canine leishmaniasis: identification of asymptomatic carriers by polymerase chain reaction and immunoblotting. Am J Trop Med Hyg 1996;55:273-7.

[97] Iniesta L, Fernandez-Barredo S, Bulle B, Gomez MT, Piarroux R, Gallego M, et al. Diagnostic techniques to detect cryptic leishmaniasis in dogs. Clin Diagn Lab Immunol 2002;9: 1137-41.

[98] Tabar MD, Roura X, Francino O, Altet L, Ruiz de Gopegui R. Detection of Leishmania infantum by real-time PCR in a canine blood bank. J Small Anim Pract 2008;49:325-8.

[99] Solano-Gallego L, Morell P, Arboix M, Alberola J, Ferrer L. Prevalence of Leishmania infantum infection in dogs living in an area of canine leishmaniasis endemicity using PCR on several tissues and serology. J Clin Microbiol 2001;39:560-3.

[100] Crawford K, Walton J, Lewis D, Tasker S, Warman SM. Infectious agent screening in canine blood donors in the United Kingdom. J Small Anim Pract 2013;54:414-7.

[101] Krause PJ, Spielman A, Telford 3rd SR, Sikand VK, McKay K, Christianson D, et al. Persistent parasitemia after acute babesiosis. N Engl J Med 1998;339:160-5.

[102] Selvapandiyan A, Stabler K, Ansari NA, Kerby S, Riemenschneider J, Salotra P, et al. A novel semiquantitative fluorescence-based multiplex polymerase chain reaction assay for rapid simultaneous detection of bacterial and parasitic pathogens from blood. J Mol Diagn: JMD 2005;7: 268-75.

[103] Boelaert M, Dujardin JC. Diagnostic PCR with Leishmania donovani specificity. Trop Med Int Health: TM IH 1999;4:789.

[104] Shulman IA. Parasitic infections and their impact on blood donor selection and testing. Arch Pathol Lab Med 1994;118: 366-70.

[105] Cardo LJ, Rentas FJ, Ketchum L, Salata J, Harman R, Melvin W, et al. Pathogen inactivation of Leishmania donovani infantum in plasma and platelet concentrates using riboflavin and ultraviolet light. Vox Sang 2006;90:85-91.

[106] Eastman RT, Barrett LK, Dupuis K, Buckner FS, Van Voorhis WC. Leishmania inactivation in human pheresis platelets by a psoralen (amotosalen $\mathrm{HCl}$ ) and longwavelength ultraviolet irradiation. Transfusion 2005;45: 1459-63.

[107] Jimenez-Marco T, Fisa R, Riera C, Girona-Llobera E, Sedeno M, Saura A, et al. Pathogen inactivation technology applied to a blood component collected from an asymptomatic carrier of Leishmania infantum: a case report. Vox Sang 2012;103:356-8.

[108] Wagner SJ, Skripchenko A, Salata J, Cardo LJ. Photoinactivation of Leishmania donovani infantum in red cell suspensions by a flexible thiopyrylium sensitizer. Vox Sang 2006;91:178-80.

[109] Jimenez-Marco T, Riera C, Fisa R, Girona-Llobera E, Sedeno M, Goodrich RP, et al. The utility of pathogen inactivation technology: a real-life example of Leishmania infantum inactivation in platelets from a donor with an asymptomatic infection. Blood Transfus = Trasfusione del sangue 2012;10:536-41.

[110] Cardo LJ, Salata J, Harman R, Mendez J, Weina PJ. Leukodepletion filters reduce Leishmania in blood products when used at collection or at the bedside. Transfusion 2006;46:896-902.

[111] Soli M, Blanco L, Riggert J, Martinez-Clavel A, Lucas C, Lunghi $M$, et al. A multicentre evaluation of a new filtration protocol for leucocyte depletion of high-haematocrit red blood cells collected by an automated blood collection system. Vox Sang 2001;81:108-12.

[112] Cardo LJ, Asher L. Transfusion medicine illustrated. Electron micrographic study of the removal of Leishmania from blood products by leukodepletion filters. Transfusion 2006;46: $315-6$. 